\title{
Making the messenger
}

The field of transcription analysis was launched with the discovery of RNA polymerase just under 50 years ago. Until then, DNA had hogged most of the molecular biology limelight - it was known to be the means of inheritance and its structure had been solved. Yet precisely how genes exerted their effects remained a mystery.

The first concrete evidence that genes specify the amino-acid sequence of proteins came in 1957, when Vernon Ingram linked a defect in the gene that caused sickle-cell anaemia with a single amino-acid change in the haemoglobin protein. The question was how the information contained in the DNA was transferred into protein. It seemed that DNA could not be directly involved, because enucleated cells could still synthesize protein. One theory was that a short-lived intermediate must carry the message from the DNA in the nucleus to the cytoplasm, where proteins were made. The prime candidate for this messenger was RNA, as it was found both inside the nucleus and in the cytoplasm, and seemed to be concentrated where proteins were being produced.

To begin to unravel this problem, Samuel B. Weiss and his assistant Leonard Gladstone set out to discover how RNA was made. Several laboratories had discovered an enzyme activity that added nucleotides onto the end of an RNA molecule. However, the enzyme responsible did not seem able to produce full-length RNA.

Weiss and Gladstone initially developed a process that placed a radioactive phosphate at the $\alpha$-position of nucleoside triphosphates, which gets incorporated into the sugar-phosphate backbone of nucleic acids. They made a crude preparation of rat livers that was enriched in cell nuclei. Incubation of labelled cytidine $5^{\prime}$-triphosphate (CTP) with the liver homogenate led to some of the label being incorporated into the RNA fraction.

The reaction required all four nucleoside triphosphates and, importantly, DNA. This was the first step to showing that DNA provided the template for the synthesis of RNA. By digesting the labelled product back to mononucleotides, the authors showed that each of the nucleotides carried a portion of the label. This, they argued, suggested that the CTP was incorporated next to each of the other nucleotides as part of a growing chain, rather than merely being tacked on to the end.
This was the first description of an RNA polymerase. A few months later, Audrey Stevens reported a similar activity in Escherichia coli, showing that the enzyme was present in both prokaryotes and eukaryotes.

Helen Dell, Associate News and Views Editor, Nature

\section{References and links}

ORIGINAL RESEARCH PAPERS Weiss, S. \& Gladstone, L.

A mammalian system for the incorporation of cytidine triphosphate into ribonucleic acid. J. Am. Chem. Soc. $\mathbf{8 1}$ 4118-4119 (1959) | Stevens, A. Incorporation of the adenine ribonucleotide into RNA by cell fractions from $E$. coli $B$. Biochem. Biophys. Res. Commun. 3, 92-96 (1960)

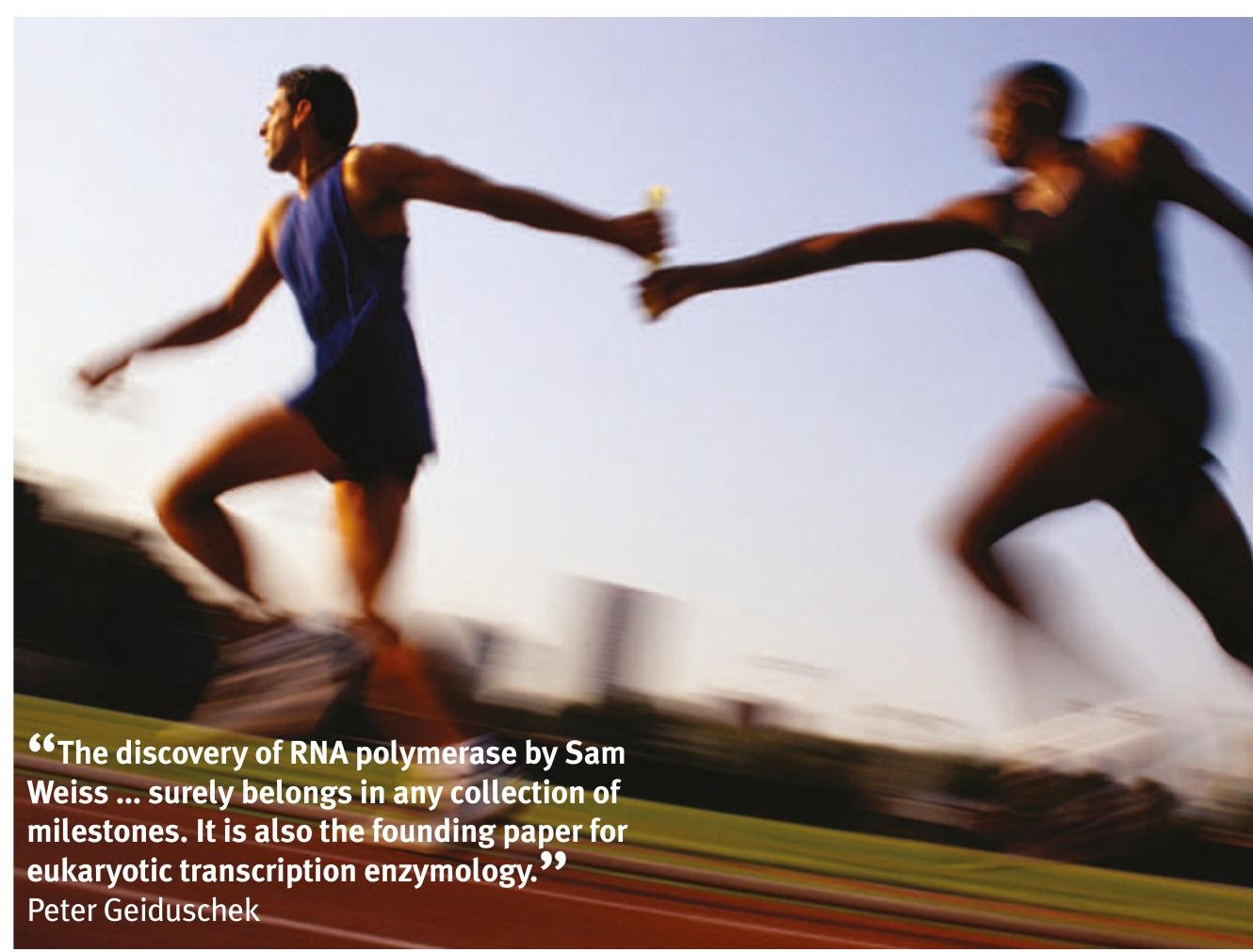

